\title{
ERRATUM
}

\section{Obituary. Charles B. Wilson, MD, 1929-2018}

TO THE READERSHIP: Two errors appeared in the article by Berger et al. (Berger MS, Garner IV, McDermott MW: Obituary. Charles B. Wilson, MD, 1929-2018. J Neurosurg 129:547-550, 2018).

Raeburn Llewellyn's name appeared incorrectly as "Lewellyn Rayburn." John Moossy's name was misspelled as "John Mossy."

The article has been corrected online as of January 11, 2019.

Mitchel S. Berger, MD

University of California, San Francisco, CA

\section{INCLUDE WHEN CITING}

Published online January 11, 2019; DOI: 10.3171/2018.12.JNS18974a.

CAANS 2019, except where prohibited by US copyright law 